\title{
Carbon Nanomaterials for Theranostic Use
}

\author{
Izabela Kościk ${ }^{1}$, Daniel Jankowski ${ }^{2}$ and Anna Jagusiak ${ }^{1, * \mathbb{D}}$
}

1 Chair of Medical Biochemistry, Faculty of Medicine, Jagiellonian University Medical College, Kopernika 7, 31-034 Krakow, Poland; izabela.koscik@uj.edu.pl

2 Faculty of Biochemistry, Biophysics, and Biotechnology, Jagiellonian University, Gronostajowa 7, 30-387 Krakow, Poland; daniel.jankowski@student.uj.edu.pl

* Correspondence: anna.jagusiak@uj.edu.pl

check for

updates

Citation: Kościk, I.; Jankowski, D.; Jagusiak, A. Carbon Nanomaterials for Theranostic Use. C 2022, 8, 3. https://doi.org/10.3390/c8010003

Academic Editor: Giuseppe Cirillo

Received: 31 October 2021

Accepted: 28 December 2021

Published: 31 December 2021

Publisher's Note: MDPI stays neutral with regard to jurisdictional claims in published maps and institutional affiliations.

Copyright: (c) 2021 by the authors Licensee MDPI, Basel, Switzerland. This article is an open access article distributed under the terms and conditions of the Creative Commons Attribution (CC BY) license (https:// creativecommons.org/licenses/by/ $4.0 /)$.

\begin{abstract}
Based on statistics from the National Cancer Institute in the US, the rate of new cases of cancer is 442.4 per 100,000 men and women per year, and more than one-third do not survive the disease. Cancer diagnosis and treatment are the most important challenges in modern medicine. The majority of cancer cases are diagnosed at an early stage. However, the possibility of simultaneous diagnosis and application of therapy (theranostics) will allow for acceleration and effectiveness of treatment. Conventional chemotherapy is not effective in reducing the chemoresistance and progression of various types of cancer. In addition, it causes side effects, which are mainly a result of incorrect drug distribution. Hence, new therapies are being explored as well as new drug delivery strategies. In this regard, nanotechnology has shown promise in the targeted delivery of therapeutics to cancer cells. This review looks at the latest advances in drug delivery-based diagnosis and therapy. Drug delivery nanosystems made of various types of carbon (graphene, fullerenes, and carbon nanotubes) are discussed. Their chemical properties, advantages, and disadvantages are explored, and these systems are compared with each other.
\end{abstract}

Keywords: graphene; graphene family nanomaterials (GFNs); nano-graphene oxide (NGO); graphene oxide (GO); reduced graphene oxide (R-GO); photosensitizer (PS); photodynamic therapy (PDT); carbon nanotubes (CNTs); carbon quantum dots (CQDs)

\section{Introduction}

The incidence of cancer diseases has increased in recent decades [1]. As a result, there is a growing demand for new methods of diagnosis, treatment, drug delivery, and the drugs themselves. The emergence of multi-drug resistance in tumor cells has raised concerns regarding long-term treatment, which resulted in the intensification of the search for such methods [2]. Nanotechnology is a revolutionary path of technological development that concerns material management on a nanometric scale that may be the answer for those concerns. Nanobiotechnology combines nanotechnology and physical sciences with biological sciences through multiple methods in developing novel tools and platforms for understanding biological systems, disease diagnosis, and its treatment. Nanomaterials are the basis for theranostics, which are nano-size or molecular level agents serving both diagnosis and therapy [3]. One of the unique materials that are used in nanobiotechnology is carbon, with many different properties, which is the basis of one of the branches of nanotechnology - carbon nanotechnology [4]. Carbon in most of its allotrope forms seems to be negligibly cytotoxic and broadly biocompatible with various agents, making it an ideal nanomaterial for research into potential applications in technology, bioelectric technology, and nanomedicine. In recent years, nanotechnology has evolved into a multidisciplinary field where basic knowledge of the electrical, optical, magnetic, and mechanic properties of nanostructures can provide a new generation of functional materials with a wide range of applications. Nanomaterials range in size from about 1 to 100 nanometers and are comparable to many biological macromolecules. Materials in this size show interesting 
physical properties, differing from both the molecular and mass scales. Nanoparticles can also be adapted to the desired shape, structure, or even chemical composition. Their high surface area as well as optical, electronic, and magnetic properties make it possible to assume that they can prove themselves as biological substances [5].

Figure 1 shows an application of carbon nanomaterials in theranostics.

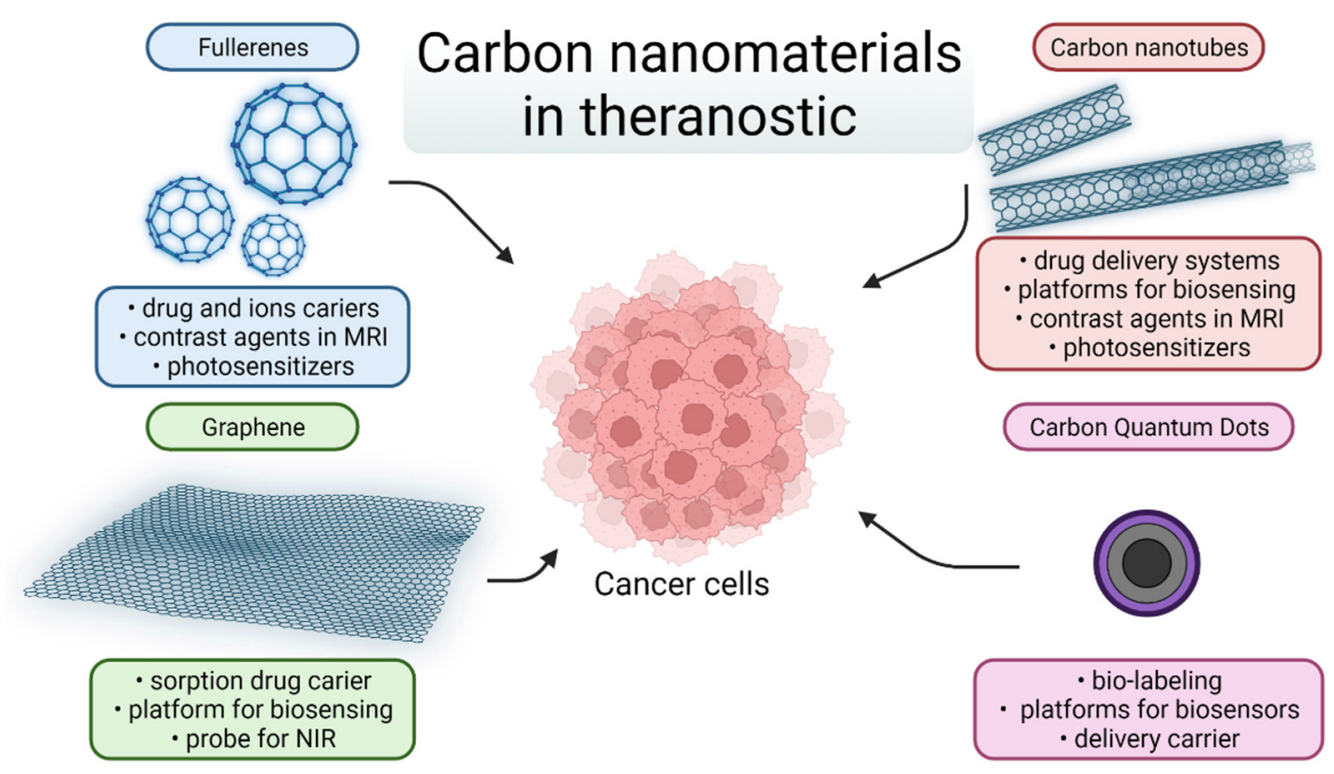

Figure 1. Examples of the use of carbon nanostructures in theranostics. The size scale is not proportional. The glow near the structures represents the functionalization and presence of different active substances. Created with BioRender.com (accessed on 30 December 2021).

Since the 1980s, carbon nanomaterials have gradually been discovered, including graphene, fullerenes, carbon nanotubes, and carbon nanofibers [6]. Carbon-based nanoparticles were designed to replace metallic nanoparticles, quantum dots, and polymer-based nanoparticles.

In this review, we delve into the biological and medical importance of carbon nanomaterials.

\section{Advantages and Disadvantages of Non-Carbon- and Carbon-Nanomaterials in Theranostics}

Nanomaterials of various origins are analyzed in terms of their use in medicine and bioengineering. The analyzes focus on the possibilities of using both in diagnostics and therapy, i.e., in theranostics. The research indicates both the advantages and disadvantages of the systems used, including nanoparticles, polymeric and metallic materials, quantum dots, microcapsules, dendrimers, and liposomes.

The surface-to-volume ratio of a nanoparticle is $35-45 \%$ times higher compared to a conventional molecule. This unique external property of the nanoparticle specific surface is a factor contributing to its high value and also influences various internal properties such as strong size-dependent surface reactivity. These unique features of nanoparticles are responsible for their multifunctional properties and interest in their application in various fields [7]. Nanoparticles can also be a contrast factor in high-resolution medical imaging MRI and can be used in therapy, especially as drug carriers for targeted drug delivery [8]. Unfortunately, just like any other material, nanoparticles also have their drawbacks.

Metallic nanoparticles or metal nanoparticles (noble metals such as gold, silver, or platinum) have relatively simple and effective techniques to obtain high purity nanoparticles on a large scale. They can be easily modified by monitoring and changing the preparation parameters. The main disadvantage is their sensitive microstructure, which can be influenced by various factors such as unwanted contamination. Most of the methods used 
to produce these nanoparticles require high energy, which generates high costs, and each method carries a different risk [7].

Polymer-based nanoparticles, depending on their type, differ in their properties, but most of them show easily modifiable physicochemical properties, low toxicity, and hydrophobicity, useful in the case of transferring poorly soluble drugs. The main disadvantage in their case is the possibility of increased cytotoxicity that may appear depending on the modifications made on the surface of nanoparticles. Some of them are also sensitive to ambient temperature and $\mathrm{pH}$. The acidic nature of, e.g., PLGA (poly(lactic-co-glycolic acid) monomers makes them unsuitable for certain drugs and bioactive molecules. It is also generally difficult to achieve optimal drug release through readily varying pharmacokinetics [9].

Luminescent quantum dots seem to be ideal for biolabeling [10]. Many other uses of carbon quantum dots have also been shown, e.g., biosensing with multi stimulus responses and delivery with various combinations with biomolecules [11]. However, there are reports that a given type of nanostructure is toxic and potentially dangerous to the environment (of which no carbon nanostructure is totally lacking).

Liposomes, which are lipid-based nanoparticles, have high loading efficiency. They can protect encapsulated drugs from early inactivation, degradation, and dilution. They may also be easily functionalized with various surface modifications and formulated into different forms for different routes of administration. Despite their spectacular possibilities, they are characterized by low stability and a complicated preparation procedure [6,9]. Carbon nanomaterials have many advantages such as the ease of covalent functionalization of their surfaces, control of hydrophobicity and hydrophilicity, and the degree of solubility in water and organic solvents [12]. Other characteristics are the possibility of creating hybrid materials with their participation [13], and fluorescence in a wide spectral range (infrared and near-infrared), useful in the diagnosis and controlled release of drugs [14]. These features lead to hope that these materials can constitute an alternative to and competition with other carriers. On the other hand, carbon nanomaterials, although seeming to be an excellent solution to the existing problems with the diagnosis and treatment of diseases, must be handled with special care since there is a possibility of toxicological effects. The influence of individual materials is not well known and may vary depending on various factors such as size, density, purity, and the location they are used on. Figure 2 presents a classification of carbon nanostructures by dimensions with some appropriate biological beings for comparison [15].

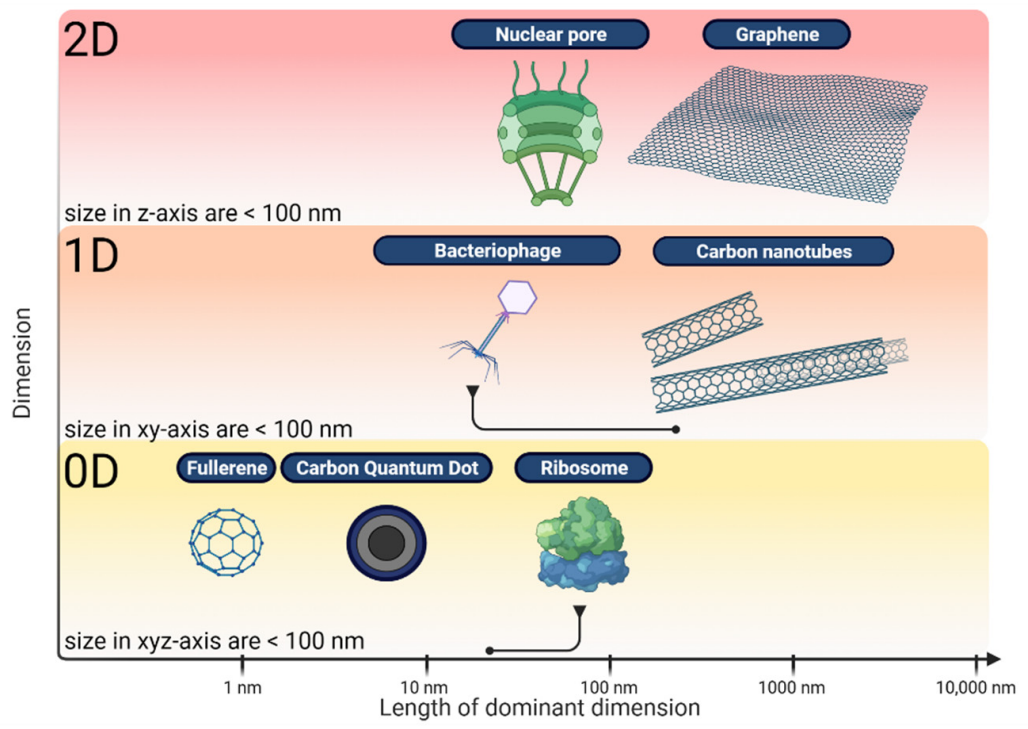

Figure 2. Dimensional classification of carbon nanostructures. The dot-end arrow indicates the precise size on the scale. The location and breadth of other structures indicate the approximate size range. Created with BioRender.com (accessed on 30 December 2021). 
Developing well-characterized nanocarriers is thus crucial to facilitating their use for biological and biomedical purposes.

\section{Carbon Materials in Theranostics}

\subsection{Graphene}

Graphene was properly isolated in 2004 by Andre Geim and Konstantin Novoselelov at the University of Manchester. They pulled graphene layers from graphite with a common adhesive tape in a process called either micromechanical cleavage or the Scotch tape technique. However, the first indications of this nanomaterial appeared as early as 1947. P. $R$. Wallace first explored the theory of graphene as a starting point for understanding the electronic properties of graphite [16].

Graphene has been received with great interest in various fields including biomedical applications. The interesting physical properties of graphene, a novel one-atom-thick two-dimensional graphitic carbon system, have led to much excitement in recent years in material science and condensed matter physics. Due to its ultrahigh surface area that is four magnitudes higher than the surface of any other nanomaterials explored for nanomedicine and easy functionalization, graphene has been intensively explored for drug and gene delivery [17].

\subsubsection{Chemistry of Graphene}

Graphene is produced from unadulterated carbon, with atoms composed and arranged into two-dimensional honeycomb lattices like graphite. Each carbon atom in graphene is attached to other carbon atoms in the same plane with a strong carbon-carbon bond, which provides excellent thermal and electrical conductivity with a low factor of thermal expansion. The interlayer binding through weak van der Waals forces makes it a soft material as opposed to diamond. The breaking strength of single-layer defect-free graphene is approximately 200 times higher than steel, making it one of the strongest materials tested.

Due to various chemical modifications, the number of layers, purity, and composition, we can classify whole graphene family nanomaterials (GFNs) [18].

The GFNs include single-layer graphene, bilayer graphene, multilayer graphene, graphene oxide (GO), and reduced graphene oxide (R-GO). Monolayer graphene is an isolated single layer of atoms bound together in a 2D planar honeycomb-like structure. A monolayer of graphene represents an extreme case where every atom has an exposed surface, which allows significantly higher drug loading capacity compared with other nanomaterials. The number of layers of graphene sheets and their thickness is important for several reasons. A larger number of layers will reduce surface area but will increase the rigidity of graphene nanomaterials and carriers required for cell penetration. A graphene flake is a mixture of graphene flakes containing a stack of graphene layers packed at $0.35-0.36 \mathrm{~nm}$ intervals. Covalent functionalization of the graphene surface is associated with a change in the degree of hybridization of the carbon atoms that build this structure from sp2 to sp3 [19].

Graphene functionalization is a method that can be applied to any member of the graphene family using polymers, small particles, nanoparticles, etc. to enhance or change the properties required for a specific application.

Primary graphene is poorly dispersed in water. Surfactants or other stabilizing agents are required to suspend graphene in biological fluids and prevent agglomeration. Therefore, graphene oxide is capable of hydrogen bonding due to polar baseline and negative charges at the edge site. Different structures with their various physicochemical properties show unique ways of interacting with cells and tissues. This may affect the functionality and biocompatibility of such systems, resulting in negative and positive effects. To be able to use these nanomaterials in biology and medicine it is important to study and understand these interactions [20]. Graphene-based materials exhibit unique interactions with nucleic acids. GO shows preferential adsorption of single-strand (ss) DNA. Using coarse-grained molecular dynamics simulations, Titov et al. [21] showed graphene forms' stable and 
functional hybrid structures with lipids, although experimental data are needed to support these simulations. Such research will be important in understanding the interaction of graphene with the lipid bilayer in the plasma membrane.

\subsubsection{Graphene in Theranostics}

In 2020, Rosa Garriga et al., examined toxicity of four carbon nanomaterials and their applications as drug delivery systems in in vitro studies in colon cancer (Caco-2) and breast cancer (MCF-7) cell lines. They combined nanodots, graphene oxide, carbon nanotubes, and reduced graphene oxide with two different drugs (camptothecin, CPT, and doxorubicin, DOX). Carbon-drug complexes resulted in improved anticancer activity compared to the free drug. Graphene oxide gives remarkable results when combined with CPT. DOX works better in a complex with R-GO [22].

CPT and DOX combined with graphene were also used by Zhang et al., They used the easiest method of making such complexes: sorption. The choice of those two drugs was not accidental because studies show a better anti-cancer effect when used together. Their observations show that the DOX or CPT sorption coefficient depends mainly on the distribution coefficient of the drug dissolved in the solution and adsorbed on the graphene carriers. As a result, it becomes possible to correct the load factor DOX and CPT in the complex folic acid (FA)-nanoscale graphene oxide (NGO)/CPT/DOX system, which is of practical importance for the clinical use of nanocarriers loaded with many drugs. Unfortunately, such systems have a major drawback: the rapid release of adsorbed drug molecules. Therefore, such carriers cannot be used in long-term therapy [23]. In another study, graphene oxide (GO) conjugated with FA was prepared as a drug delivery system. Additionally, using the hydrophobic interactions of the $\pi-\pi$ stacking type, a photosensitizer was attached to this system. Such nanocarriers significantly increase the accumulation of the photosensitizer in cancer cells and lead to high photodynamic efficiency after irradiation of cells [24].

In 2008, Sun et al., introduced the use of single-layer NGO in cancer theranostics as a platform for combined diagnosis and therapy [25]. The material, showing intrinsic photoluminescence (PL) exploitable for live cell imaging in the NIR, was coated by polyethylene glycol (PEG) to improve its solubility and biocompatibility. Moreover, NGO imaging properties were combined with its loading capability, resulting in a theranostic nanoplatform. To this end, the anticancer drug DOX was bound to NGO sheets, which were functionalized with the B-cell-specific antibody Rituxan (anti-CD20) for the in vitro selective binding and killing of Burkitt's lymphoma cells. Sustained Raji B cell growth inhibition $(\sim 80 \%)$ was observed after $2 \mathrm{~h}$ incubation with the nanosystem at a DOX concentration of $10 \mu \mathrm{mol} / \mathrm{L}$ followed by $48 \mathrm{~h}$ incubation in fresh cell medium.

In 2018, Wang's team conducted an experimental optical sensing system setup for living cells of colorectal cancer. They used a graphene-based optical biosensor (GOB). This biosensor detected an ultrafast RI change generated by weak ultrasonic waves. By using the GOB they demonstrated ultra-sensitive and real-time sensing of unlabeled cancer cell responses to paclitaxel during early drug delivery for the first time. Compared with high concentration paclitaxel treatment, colorectal cancer cells exhibited more intense and faster responses to low concentration paclitaxel treatment. Two colorectal cancer cell lines, LoVo and HCT116, confirmed this counterintuitive response [26].

A promising therapeutic technique is cell hypothermia, i.e., photothermal ablation of neoplastic tumors, requiring multiple passes of the healing agent through the capillary system [27]. The nanoparticles used in this technique should exhibit the increased stability that the presence of graphene can provide [28].

In diagnostics, peptide sensors with graphene were proposed, which would allow for the early detection of neoplasms [29]. 


\subsubsection{The Advantages and Disadvantages of Using Graphene in Medicine}

Graphene and graphene-based materials have many properties and are easily modifiable. Those specific qualities such as biocompatibility, stiffness, flexibility, and thermal properties have attracted considerable interest. The nanoparticles have greater permeability and precise control over release time which has led to use in controlled drug delivery systems and theranostics. The ability of graphene to be loaded with drug molecules with aromatic rings, interaction with nucleic acids, and the possibility to attach various chemically active groups to the basic lattice structure has allowed researchers to build graphene-based sensors for detecting biochemical molecules (and ultimately selected cells [30]). Graphene derivatives are used as drug packaging and enzyme immobilization surfaces [31] and also as vectors in gene therapies [32].

Carbon-based nanomaterials are not biodegradable, leading to concerns about potential toxicity and environmental hazards [33]. However, Kotchey et al., conducted research in which he was able to demonstrate that GO was susceptible to biodegradation using oxidative attack with hydrogen peroxide and horseradish peroxide. Unfortunately, this has not yet been achieved in the case of the R-GO. This research could lead to the potential design of safer biodegradable materials based on graphene to eliminate their environmental and health hazards $[19,34]$. The major limitation of pristine graphene is its hydrophobic nature and its unstable homogenous dispersion, which prevents its application in many areas of biomedical research [35].

It seems that thorough cleaning, proper selection of reducing agents or surfactants and proper preparation of the material reduces the negative biological effect (such as apoptosis, increased cell death, cytoskeleton disorders, or inflammation [36,37]). In addition, the observed effects can be used in advanced therapies, e.g., in new generation anti-cancer drugs that induce controlled apoptosis of cancer cells.

\subsection{Fullerenes}

In 1985, Harold Kroto, working with James R. Heath, Sean O'Brien, Robert Curl, and Richard Smalley, discovered fullerenes in soot produced by the evaporation of carbon in a helium atmosphere. Discrete peaks appeared in the mass spectrum of the product corresponding to molecules with the exact mass of 60 or 70 carbon atoms, namely C60 and C70. The team identified their structures as "buckyballs". The name fullerene is an abbreviation of "buckminsterfullerene" from the name of the American architect who popularized this structure [38].

\subsubsection{Chemistry of Fullerenes}

Fullerenes have attracted the attention of scientists not only for their unique and beautiful structure but also as materials for possible applications in engineering and medicine. A pioneering nanoparticle, fullerene, is an allotropic form of carbon, in addition to diamond, graphite, and graphene, with a specific geometry, size, and surface characteristics and a uniquely regular spherical structure with strongly nonpolar characteristics [39]. Many fullerenes with empty carbon cages have been synthesized and functionalized by various chemical methods. The biomedical effects of such "empty" fullerenes are mostly defined by chemical groups $\mathrm{C}_{60}$, attached to the fullerene cage that can vary in size $(\mathrm{C} 60, \mathrm{C} 70$, etc.). This empty space inside can be adapted to various atoms, including radioactive atoms, which can, for example, be used in diagnostics. These features make it possible to use fullerenes in lipid-like systems serving as reservoirs and even to penetrate cell membranes. Furthermore, there are so-called endohedral metallofullerenes (EMFs) that contain one or more atoms, among them lanthanides or heavy elements such as $\mathrm{Pb}$ or $\mathrm{Bi}$, trapped in a coal cage. Fullerenes have a structure composed of $\mathrm{sp} 2$ carbons with unique chemical properties [40,41].

The largest ones consist of 1500 carbon atoms and the smallest 20. However, the existence of C20 fullerenes is only theoretical, as not all fullerenes are chemically sta- 
ble. The most abundant fullerenes in the synthesized composition are the C60 and C70 molecules [42].

C60 consists of 60 carbon atoms with C5-C5 single bonds ( 12 pentagons) and C5=C6 double bonds ( 20 hexagons). Delocating the 30 double bonds and sharing all the $\pi$ electrons gives the molecule high stability. Indeed, every $2 n+20$ carbon fullerene contains " $\mathrm{n}$ " hexagons. C60 and C70 are produced at $1000{ }^{\circ} \mathrm{C}$, and the concentration increases with increasing pulse duration.

\subsubsection{Fullerenes in Theranostics}

In vitro and in vivo cytotoxicity studies in human and animal cells showed no cytotoxicity or very low acute toxicity C60, which was tested in various fields of medicine [43].

The following research directions can be distinguished in research on fullerenes: their use in medicine (anti-enzyme, anti-viral, DNA splitting), use as new contrasting agents in NMR-based tomography (MRI), and use as radioactive indicators and pharmaceutical preparations in photodynamic therapy (PDT).

One of the approaches to using fullerenes in theranostic medicine is to encapsulate a $\mathrm{Gd}$ (gadolinium) center within a fullerene. The $\mathrm{Gd}^{3+}$ ion is encapsulated in the fullerene cage, which is a structure that preserves the properties of the metal ion, avoids any leakage, and thus prevents its dissociation in vivo. Many types of "gadofullerenes" have been developed by using specific chemical modifications. Li et al., synthesized an encapsulated gadofullerene and then functionalized the fullerene with cytokine interleukin-13, which is overexpressed in human glioblastoma cell lines. The compound was further functionalized with amine groups, which can maintain a positive charge at physiological $\mathrm{pH}$, to further increase water solubility and tumor uptake. While this group of researchers has yet to report cytotoxicity studies, the preliminary tumor uptake and MRI studies are promising [44].

The photochemical properties of fullerenes also indicate the possibility of their direct application in medicine in local photodynamic therapy. The ability of fullerenes to generate active singlet oxygen as a result of photochemical activation of the system is most often used. Chiang et al., performed a preliminary in vivo photodynamic therapy (PDT) study using hydrophilic nanospheres formed from hexa(sulfo-n-butyl) -C60 (FC4S). This study was performed in ICR mice bearing sarcoma subcutaneous tumors. FC4S was administered intraperitoneally or intravenously and then irradiated with an argon ion laser beam or an argon-pumped dye-laser. It has been found that inhibition of tumor growth is more effective using a low wavelength, i.e., a $515 \mathrm{~nm}$ laser that is better absorbed than a $633 \mathrm{~nm}$ laser. This method of administration turned out to be slightly better in inhibition effectiveness and demonstrate the potential use of fullerenes as PS for PDT of cancer [45]. Another example is the tumor loss of sarcoma in mice by Tabata et al., after application of C60 coupled with poly (ethylene glycol) and exposure to irradiation [46].

Other imaging strategies may have been used in non-invasive medical diagnosis: optical imaging, computed tomography, and ultrasound.

Recently, an attractive new therapeutic concept called "acoustic explosion" was suggested for some functionalized fullerenes, polyhydroxy fullerenes (PHFs), and carboxy fullerenes $(\mathrm{CFs})$. Functionalized fullerenes maintain the glow in the presence of continuous laser irradiation in the presence or absence of oxygen. These types of studies were carried out on cancer cells in which, after irradiation, a faint click was heard, indicating the photoacoustic properties of these fullerenes [47]. Fullerenes associated with metals from the lanthanide group (lanthanometallofulereins) are used in diagnostics and therapeutic medicine as radioactive tracers.

\subsubsection{The Advantages and Disadvantages of Using Fullerenes in Medicine}

The presence of the large surface allows the fullerene to enclose in its volume separate atoms and molecules.

Novel photosensitizers (PSs) prepared from fullerenes have additional MRI activity. Fullerenes are more photostable and demonstrate less photobleaching compared to the 
traditional PS used for PDT. Fullerenes can be attached to light-harvesting antennae and electron transfer dyads to change the wavelengths of absorption towards the red end of the spectrum. These attached antennae can encourage charge separation mechanisms and electron transfer mechanisms. Fullerenes can also be chemically modified to alter the action and dosage of the drug in biological systems.

Fullerenes (both pristine and functionalized) can kill cancer cells after incubation. They can also inactivate viruses, bacteria, and fungi (in vitro). Studies in vivo report that they can destroy or inhibit tumors growing in mice [48]. Pristine fullerenes are highly hydrophobic with a propensity to aggregate in aqueous environments. Even when they are functionalized with water-soluble polar groups, this drawback may not be entirely overcome.

Fullerenes are characterized by a non-toxic, inert molecular structure. After fullerenes enter the body, they may be internalized by different types of cells and induce various changes inside the cells, such as viability, proliferation, inflammation responses, and oxidative responses. C60 itself has a relatively high molecular weight $(720 \mathrm{~g} / \mathrm{mol})$. When substantial additional moieties are conjugated to the cage, the MW can rise significantly.

The main limitation is the release of metal ions in vivo during metabolic processes and the subsequent toxicity. Another limitation in their use is the high cost of obtaining them.

\subsection{Carbon Nanotubes}

Carbon nanotubes (CNTs) made of wrapped graphene sheets in needle-like shapes have many physical but also mechanical and chemical properties. Many sources indicate 1991 as the year of their discovery and attribute it to Sumio Iijima. We owe the production of multi-walled nanotubes today to Morinobu Endo, who in 1976 observed hollow tubes made of coiled graphite synthesized by the chemical vapor growth technique, and today the mass production method used is called the Endo process.

\subsubsection{Chemistry of Carbon Nanotubes}

Depending on the number of graphene layers from which a single nanotube is made, they are classified as single-walled nanotubes or multi-walled nanotubes. The latter can also be divided into two, three, and multi-walled, and their structures are described in two different ways: the Russian doll model and parchment model. In the Russian doll model, graphene layers are arranged in concentric cylinders, while in the parchment model, a single layer of graphene is wrapped like a rolled newspaper. Due to their abilities, nanotubes have aroused great interest among scientists, motivated by their potential biological use in medicine. Nanotubes are hydrophobic; therefore, compared to other nanoparticles, they exhibit poor solubility in aqueous solvents, which makes it difficult to disperse them uniformly. As a result, it becomes problematic to evenly combine them with the active substance. Various methods for dispersing CNTs in water and non-aqueous media have been investigated in recent years; considerable attention was paid to both physical issues and chemical techniques. Physical methods include ultrasound [49], plasma treatment [50], and radiation [51]. Several chemicals are also used to disperse CNTs, including mineral acids, inorganic monovalent salts, inorganic peroxides, salts of organic acids and sand, aromatic compounds, polymers, and biomolecules. Therefore, to fulfill the role of carriers, they must undergo certain modifications. Such functionalization is carried out using two methods: exohedral and endohedral. To carry out exohedral functionalization, the active substance is attached through covalent or non-covalent bonds. In non-covalent functionalization, substances interact with the nanotube through $\pi-\pi$ bonds or van der Waals forces. The task of covalent functionalization on cavities and side walls is to permanently bind individual compounds to the surface of the tube. Functionalization of defects occurs mainly in - $\mathrm{COOH}$ groups. Functionalization of the side walls takes place directly on the nanotube carbon atoms and consists of addition to double bonds, causing a change in the hybridization of carbon atoms from sp2 to sp3, which significantly changes the electron properties of the nanotube. CNTs can be used as diagnostic tools for the 
early detection of cancer. The second method consists of filling the void with various polar substances. Recent studies show that functionalized CNTs can cross the blood-brain barrier. There is no single mechanism for cellular uptake of CNTs but rather three different mechanisms that can each predominate depending on several factors. These three different processes are: (i) internalization by endocytosis; (ii) internalization by phagocytosis, and (iii) direct translocation through the plasma membrane. Endocytosis describes the engulfment of a macromolecule by the cell (e.g., proteins and antibodies) through the formation of a vesicle that is then generally routed to endosomes and lysosomes. Phagocytosis is similar in principle to endocytosis, with the difference that the particles taken up are considerably larger (e.g., bacteria with dimensions of less than $1 \mu \mathrm{m}$ ), and the cell type responsible is often a professional phagocytic cell. It has also been reported that CNTs can behave similarly to cell-penetrating peptides, which allow translocation through the plasma membrane of mammalian cells due to the presence of polycationic regions. It has been stated that cationic functionalized CNTs are similar to cell-penetrating peptides both in charge and morphology and may penetrate plasma, likely through endocytosis [52].

\subsubsection{Carbon Nanotubes in Theranostics}

The ability to easily penetrate cell membranes [53], demonstrated by carbon nanotubes (CNTs) has provided an opportunity to study them as carriers for drug delivery systems (DDS) and theranostics [54,55]. Heister et al., developed a DDS by combining DOX, a monoclonal antibody, and fluorescein, all attached on the sidewalls of oxidized single-walled CNTs (SWCNTs). The monoclonal antibody recognized the tumor marker, carcinoembryonic antigen, and allowed the binding of DOX to the antigen target sites on cancer cells. The delivery of SWCNT-DOX complexes to WiDr colon cancer cells resulted in penetration into cancer cells, followed by the release of DOX to the nucleus, whereas SWCNTs remained in the cytoplasm.

In 2013, Chatterjee et al., conducted research with the use of an electronic sensor made of nanotubes. The method is quick and cheap, allowing scientists to carry out many trials. The biosensor operation is based on the identification of biomarkers due to solubility, polarity, and chemical associations. Water, methanol, isopropanol, ethanol, acetone, 2-butanone, and propanol were found to be polar vapors, lung cancer biomarkers. Chloroform; benzene; o-xylene; n-decane; 1-hexene; toluene; styrene; n-propane; cyclohexane; 1, 2, 4-trimethyl benzene; and isoprene were discovered as nonpolar vapors. SWCNTs, coated with nonpolymeric organic substances, can detect volatile organic component (VOC) changes as cancer biomarkers, which allows them to quickly diagnose and proceed to treatment [56].

In 2020, Golubewa's team demonstrated that glioblastoma cells are capable of efficient accumulation of SWCNTs. As a result, relatively large agglomerates were formed which enable photo-induced destruction of cancer cells through picosecond laser irradiation. They also applied the CARS imaging technique and showed that it can be effectively used for both the visualization of a cancer cell and its photo-induced SWCNT-conditioned destruction, providing convincing evidence that this method is a powerful tool for nanotheranostics. The advantage of using stable SWCNT suspensions instead of conventional NPs in photoacoustic therapy is that only those cells in which agglomerates have formed are destroyed, and free nanotubes in the environment are photoacoustically inactive, so they do not threaten adjacent tissues and fluids [57].

CNTs are used in diagnostics as a contrast agent in the magnetic resonance imaging (MRI) method. The most common research was with gadolinium chelates that can be incorporated into CNTs [58]. CNTs can also serve in cell imaging due to fluorescence in the NIR region. A great advantage of CNTs is that they do not affect the viability of the diagnosed cells [59].

\subsubsection{The Advantages and Disadvantages of Using Carbon Nanotubes in Medicine}

Biodistribution and biodegradability of CNTs from the point of view of their potential application in living organisms is a very important issue. The studies by Weng et al., and 
Singh et al., showed that the body-fluid-soluble hydrophilic nanotubes showed no toxicity or lethal effects [60].

The study of Chłopek et al., confirmed good biocompatibility of nanotubes similar to that of polysulfone currently used in medicine [61]. One of the main differences between single-walled nanotubes and multi-walled nanotubes is the useful electrical properties of the former. In the case of multi-walled nanotubes, their properties depend on the number of layers. The main advantages of nanotubes are their mechanical, thermal, kinetic, and electric properties-tensile strength, flexibility, and good heat conduction.

On the other hand, there are concerns about the cytotoxicity of this nanomaterial due to its physical similarity to asbestos fibers [62]. CNTs show a concentration dependence of cytotoxicity [63]. In addition, the purity of CNTs may also influence their cytotoxicity. Unpurified SWCNTs tend to cause greater cytotoxicity [64].

Moreover, the length of CNTs may also affect their toxicity. It has been shown that the longer the fibers, the greater toxicity influence on cells or tissues [65]. It should be kept in mind that the toxicity of CNTs depends on the degree of surface functionalization and the type of functional groups attached.

\subsection{Carbon Quantum Dots}

Carbon quantum nanodots, also known as carbon dots (CQDs) or C-dots, are small carbon nanoparticles (less than $10 \mathrm{~nm}$ in size) discovered accidentally by $\mathrm{Xu}$ et al., in 2004 during the purification of single-walled carbon nanotubes [66]. In 2006, Sun et al., observed luminescence in carbon-based particles during laser ablation of carbon sources in the presence of water [67]. The simplicity of the synthesis used by them aroused interest in the study and properties of carbon nanodots.

\subsubsection{Chemistry of Carbon Quantum Dots}

There are many methods of obtaining CQDs, and each of them has its own advantages, but particular attention was paid to CQDs produced from natural resources, the production of which was less expensive than obtaining them by oxidation of mineral graphite. The interest in using CQDs grew with each newly discovered property. Their low toxicity, high biocompatibility, aqueous solubility, and ease of making modifications allowed for attempts to use them as a drug carrier.

Because CQDs involve non-homogeneous entities, there are numerous methods for producing them. These methods can be classified as bottom-up or top-down. The harsh top-down methods include chemical (strong oxidizing acids) or laser ablation and electrochemical carbonization. The more gentle and eco-friendly bottom-up methods include microwave irradiation and hydrothermal/solvothermal treatment [68]. Using microwave irradiation on sucrose as the carbon source and diethylene glycol (DEG), green luminescent CQDs were obtained within one minute [11].

Hydrothermal carbonization (HTC) is a popular approach for preparing CQDs. Typically, carbon-yielding compounds are subjected to heat treatment in high boiling point organic solvents, followed by extraction and concentration. CQDs were synthesized using HTC from a variety of precursors including glucose, citric acid, chitosan, banana and orange juice, mushrooms, and protein $[69,70]$.

A variety of surface modifications have been reported through the surface chemistry or interactions, such as covalent bonding, coordination, $\pi-\pi$ interactions, and sol-gel technology. Doping is another widely used method for tuning the photoluminescence (PL) of CQDs, with elements such as N, S, and P being used [71,72].

Recently, work has been conducted on new hybrids consisting of CQDs and an inorganic nanoparticle core (iron oxide, zinc oxide, silica, and titanium). The resulting hybrids integrate the fluorescent properties of CQDs with the magnetic, optical, or mechanical properties of the oxide cores. Such hybrids hold great promise as magneto-optical biolabeling agents $[11,70]$. 
One of the most interesting features of CQDs, especially from application-oriented perspectives, is their photoluminescence. The PL properties of the CQDs can be tuned via modification as described above.

\subsubsection{Carbon Quantum Dots in Theranostics}

Carbon nanodots may be used in photodynamic treatment (PDT) as photosensitizers (PSs). With the increasing demand for better cancer diagnosis and treatment, many studies address the use of quantum dots in photodynamic therapy (PDT), which is incredibly successful, and the manner in which this method is carried out allows us to minimize side effects. By combining multiple photosensitizers, we may attain a high degree of specificity and selectivity. The CQDs @ PtPor compound, which was developed by the team of Wu et al., in 2018, was obtained as a result of the electrostatic interaction of the porphyrin tetraplatin (PtPor) complex with negatively charged CQD. This complex shows high biocompatibility, easily disperses in water, has good stability, and has the ability to detect the fluorescence of the photosensitizer. At the same time, it was proved that this complex is much more effective at using quantum dots than the PtPor compound itself. It also demonstrates high therapeutic efficacy against neoplastic cells, which indicates a great potential for clinical application in cancer patients [73].

In 2014, the team of Zheng et al., undertook the creation of a complex based on quantum dots with the aim of obtaining a bioimaging agent. Quantum dots are a suitable starting point for drug development since they are subject to cellular uptak and fluorescence in cells and may form different complexes. The team created a CQD-Oxa complex synthesized by a condensation reaction between the amine groups of oxaliplatin. It combines the optical properties of carbon nanodots with the anti-tumor function of oxaliplatin as a whole. Together, they act as a drug carriers and enable controlled drug release due to the reducing environment of cancer cells. The intensity of the CQD-Oxa fluorescence makes it possible to monitor the course and distribution of drug molecules. This was used to observe tumor reduction in mice (H22 liver cancer). These studies show that tumor size decreased monotonically with the duration of CQD-Oxa treatment. The tumor volume initially decreased from 535.2 to $46.6 \mathrm{~mm}^{3}$ after 6 days, which means that $91.3 \%$ of the tumors healed [74].

Lanthanide hybridized quantum dots (Ln-CQDs) were also used as a bioimaging agent. The synthesis was carried out by the $\mathrm{Wu}$ team with the use of a facile one-pot hydrothermal method using citric acid as the carbon precursor and $\mathrm{Yb}^{3+}$ or $\mathrm{Nd}^{3+}$ as a doping ion. The hybridized quantum dots have found application in multicolor cell-imaging due to strong blue emission under UV excitation. They have also been tested for cytotoxicity, and the results confirmed that they may be used in biomedical applications [75]. Other similar complexes used in bioimaging applications are CQNDs-DOTA-Ln [76].

In 2017, the Ko team created Herceptin (HER)-labeled quantum dots to obtain a theranostic agent targeting HER2 overexpressing tumors. This system was also supposed to use the quantum dots as a bioimaging agent platform. Those complexes have been synthesized through an easy coupling reaction and can form even more advanced complexes with drugs such as doxorubicin (DOX). Blue emission (from QD) of this complex enables rapid diagnosis, and HER enables efficient, targeted accumulation of these cells. The release of DOX can be easily controlled by $\mathrm{pH}$ and temperature changes. Such a complex offers versatility in the treatment of cancer and allows for its quick diagnosis, which, in the case of breast cancer, is often a critical factor in its cure [77].

\subsubsection{The Advantages and Disadvantages of Using Carbon Quantum Dots in Medicine}

There are several ways to make CQDs, giving complete control over the synthesis process and its related costs. At the same time, it was confirmed that they show great inhibition against various types of cancer such as MCF-7 or MDA-MB-231 (human breast cancer cells). The advantage of this carrier is also the ease of introducing modifications and adapting them to the uptake according to cells' needs. Additionally, the high tumor- 
to-background fluorescence contrast and low fluorescence levels in other tissues and organs demonstrated the suitability of CQDs to act as photosensitizers as they are able to localize selectively into tumors. A great advantage is the high solubility of this carbon nanomaterial [78].

One of the biggest disadvantages is nonspecific cellular binding, depending on the type of surface functional group that may impact the final result. Quantum dots may also be subject to nonspecific protein adsorption to the quantum dot surface, specifically adsorption of a $66 \mathrm{kDa}$ serum protein albumin presented in standard blocking solutions [79].

\section{Summary}

Current cancer treatments are highly invasive. This is often associated with surgery, chemotherapy, and radiation therapy, which work at a later stage with many side effects. Scientists and medical professionals have made many different attempts to counter them. However, the main problem with any cancer treatment is attaining the desired concentration of therapeutic agents at the tumor sites so that cancerous cells are destroyed while the damage to normal cells is minimal. Keeping this in mind, it is especially important to make single agents with incredible potential to provide the required input in cancer prevention, detection, and treatment. In this review, we attempt to highlight the advances made so far in carbon nanobiotechnology and its application in medicine. It can now be seen that the use of these nanomaterials in the diagnosis and therapy of cancer will be determined by the systematic determination of the benefits they offer, as opposed to the risks they carry.

Progress in the medical sciences depends on the use of knowledge and materials that we have. Carbon nanostructures have been shown in prior studies to have theranostic applications. There are several carbon nanostructures, their derivatives, and their modifications used in theranostics, as outlined in Table 1. A well-designed nanosystem can be used not only for treatment but also to make a diagnosis. Carbon nanomaterials allow us to enhance them and match our needs depending on their capabilities. From the research conducted, we already know that interfacial, physical-chemical, and optical features allow us to use them to imagine multimodal and selective non-invasive tumor eradication. Each type of nanosystem seems to have a different advantage, but due to their construction, platforms can be designed that exhibit even greater abilities for imaging, monitoring, and detecting tumors.

Table 1. Various forms of carbon nanostructure, their derivatives, alterations, and theranostics applications.

\begin{tabular}{|c|c|c|c|c|}
\hline & $\begin{array}{l}\text { Graphene Family } \\
\text { Nanomaterials }\end{array}$ & Fullerenes & Carbon Nanotubes & Carbon Quantum Dots \\
\hline Derivatives and members & $\begin{array}{l}\text { Mono-, bi-, multilayer } \\
\text { graphene } \\
\text { Graphene oxide (GO) } \\
\text { Reduced GO }\end{array}$ & $\begin{array}{c}\text { C60, C70 and others } \\
\text { Endohedral } \\
\text { metallofullerenes }\end{array}$ & $\begin{array}{l}\text { Single-walled carbon } \\
\text { nanotubes (SWCNTs) } \\
\text { Multi-walled carbon } \\
\text { nanotubes (MWCNTs) }\end{array}$ & $\begin{array}{l}\text { Graphene quantum dots } \\
\text { Carbon quantum dots }\end{array}$ \\
\hline Modification & $\begin{array}{c}\text { Oxidation } \\
\text { To-COOH: } \\
\text { PEG, folic acid, chitosan } \\
\text { To -OH: } \\
\text { Ether-carboxyl } \\
\text { Cycloaddition } \\
\text { Surface coating by } \\
\text { sorption (non-covalent): } \\
\text { Ni/Au } \\
\text { Aptamers } \\
\text { Therapeutic agents } \\
\text { Polymers (PEI) } \\
\text { Fe } \mathrm{O}_{4} \\
\text { BSA, proteins }\end{array}$ & $\begin{array}{c}\text { Oxidation: } \\
\text { Poly-hydroxylation and } \\
\text { carboxylation } \\
\text { PEGylation } \\
\text { Specific covalent } \\
\text { functionalization: } \\
\text { Glycosylation } \\
\text { Cationic/anionic groups } \\
\text { Encapsulation and } \\
\text { chelation of lanthanide } \\
\text { ions (e.g., Gd }{ }^{3+} \text { ) } \\
\text { Cyclodextrin sorption } \\
\text { complex }\end{array}$ & $\begin{array}{c}\text { Oxidation } \\
\text { To -COOH: } \\
\text {-PEG, folic acid } \\
\text { Cycloaddition } \\
\text { Surface coating by } \\
\text { sorption (non-covalent): } \\
\text { BSA, proteins } \\
\text { Glycolipids } \\
\text { Surfactants } \\
\text { Fe }_{2} \mathrm{O}_{3} \\
\text { DNA }^{-} \\
\text {PEGylated phospholipids } \\
\text { Polysaccharides } \\
\text { Surface amination }\end{array}$ & $\begin{array}{c}\text { Covalent coating with } \\
\text { amine-containing agents } \\
\text { to oxygen-containing } \\
\text { groups } \\
\text { Chelation of lanthanide } \\
\text { ions (e.g., Eu }{ }^{3+} \text { ) } \\
\text { Sol-gel technique } \\
\text { Doping with elements } \\
\text { such as N, S, P } \\
\text { Nanohybrids with } \\
\text { inorganic nanoparticles } \\
\text { (e.g., iron oxide, zinc } \\
\text { oxide, silica, and titania) }\end{array}$ \\
\hline
\end{tabular}


Table 1. Cont.

\begin{tabular}{|c|c|c|c|c|}
\hline & $\begin{array}{l}\text { Graphene Family } \\
\text { Nanomaterials }\end{array}$ & Fullerenes & Carbon Nanotubes & Carbon Quantum Dots \\
\hline Use in theranostics & $\begin{array}{c}\text { Drug/gene delivery and } \\
\text { imaging } \\
\text { Photodynamic therapy } \\
\text { Tissue engineering } \\
\text { Antibacterial activity } \\
\text { Biosensing }\end{array}$ & $\begin{array}{l}\text { Drug/gene delivery } \\
\text { Magnetic resonance, } \\
\text { photoacoustic imaging } \\
\text { Photodynamic, } \\
\text { photothermal therapy } \\
\text { Enzyme inhibition } \\
\text { Antioxidants }\end{array}$ & $\begin{array}{l}\text { Photo-thermo-acoustic } \\
\text { therapy } \\
\text { Magnetic resonance, } \\
\text { imaging } \\
\text { Drug/gene/peptide } \\
\text { delivery } \\
\text { Biosensing }\end{array}$ & $\begin{array}{c}\text { Drug/gene delivery and } \\
\text { imaging } \\
\text { Photodynamic therapy } \\
\text { Biosensing }\end{array}$ \\
\hline References & {$[12,20,26,30,80,81]$} & {$[45,47,48,63]$} & {$[50,52,53,55,57,59,63]$} & {$[11,70,80,82]$} \\
\hline
\end{tabular}

The main factors affecting the mechanical properties of nanocomposites are the dispersion of carbon nanomaterials and their interactions with other compounds. For example, due to the CNTs, fullerene, and CQD structures, they are easier to disperse and create composites than graphene. In turn, the challenges associated with the achievement of graphene alignment in polymer composites remain unresolved. The functionalization of carbon nanomaterials is an effective way to improve their dispersion. In turn, the advantage of graphene over other nanomaterials is its mechanical properties resulting from a large, flat surface. Composites with a share of CNTs and fullerenes often depend on the one-dimensional surface where the effect is much weaker.

It is important to distinguish between chemical and more delicate biochemical functionalization. The attaching of, e.g., antibodies to the carbon nanostructures can significantly increase the selectivity of the applied therapy. Carbon nanostructures can be imagined as the skeleton of a given entity. However, individual specific functions are performed by compounds closer to the cells, e.g., proteins, lipids.

As a result of the use of modern nanotechnology, it is possible to speed up diagnosis, reduce side effects, and increase the effectiveness of therapy. Rapid diagnosis combined with immediate therapy can, in many cases, be a turning point on the way to recovery. In the last dozen years, the interest in nanoparticles and their use has increased due to their already comprehensive applications. Current research shows that their physicochemical properties can be used in many ways, for example, to strengthen cancer resistance through vaccination, depo effects, or targeted drug delivery. These vaccines can provide preventive protection against cancer development by activating multi-antigenic immunity with the potential to significantly improve the humoral and cellular response.

The use of nanotechnology to create carriers also has its disadvantages, such as the potential immunogenicity of the drugs used or the general cytotoxicity caused by normal cellular uptake. A better understanding of the interactions between nanomaterials, the immune system, and cancer itself will overcome these drawbacks and advance nanomedicine [83].

Author Contributions: Conceptualization, I.K. and A.J.; methodology, I.K. and D.J.; software, D.J.; validation, I.K., D.J. and A.J.; formal analysis, I.K., D.J. and A.J.; investigation, A.J.; resources, I.K.; data curation, I.K., D.J.; writing—original draft preparation, I.K.; writing—review and editing, D.J. and A.J.; visualization, D.J.; supervision, A.J.; project administration, I.K.; funding acquisition, A.J. All authors have read and agreed to the published version of the manuscript.

Funding: This work was financially supported by the National Science Centre, Poland (grant no. 2016/21/D/NZ1/02763) and Ministry of Science and Higher Education (grant no. N41/DBS/000715).

Institutional Review Board Statement: Not applicable.

Informed Consent Statement: Not applicable.

Conflicts of Interest: The authors declare no conflict of interest. The funders had no role in the design of the study; in the collection, analyses, or interpretation of data; in the writing of the manuscript; or in the decision to publish the results. 


\section{References}

1. Cancer Statistics. Available online: https://www.cancer.gov/about-cancer/understanding/statistics (accessed on 19 November 2021).

2. Carbone, A.; Vaccher, E.; Gloghini, A.; Pantanowitz, L.; Abayomi, A.; de Paoli, P.; Franceschi, S. Diagnosis and management of lymphomas and other cancers in HIV-infected patients. Nat. Rev. Clin. Oncol. 2014, 11, 223-238. [CrossRef]

3. Janib, S.M.; Moses, A.S.; MacKay, J.A. Imaging and drug delivery using theranostic nanoparticles. Adv. Drug Deliv. Rev. 2010, 62, 1052-1063. [CrossRef] [PubMed]

4. Singh, A.; Dubey, S.; Dubey, H.K. Nanotechnology: The Future Engineering. Int. J. Adv. Innov. Res. 2019, 6, 230-233.

5. Yang, K.; Wan, J.; Zhang, S.; Zhang, Y.; Lee, S.-T.; Liu, Z. In Vivo Pharmacokinetics, Long-Term Biodistribution, and Toxicology of PEGylated Graphene in Mice. ACS Nano 2011, 5, 516-522. [CrossRef] [PubMed]

6. Parveen, K.; Banse, V.; Ledwani, L. Green synthesis of nanoparticles: Their advantages and disadvantages. AIP Conf. Proc. 2016, 1724, 020048. [CrossRef]

7. Jamkhande, P.G.; Ghule, N.W.; Bamer, A.H.; Kalaskar, M.G. Metal nanoparticles synthesis: An overview on methods of preparation, advantages and disadvantages, and applications. J. Drug Deliv. Sci. Technol. 2019, 53, 101174. [CrossRef]

8. Torchilin, V.P. Targeted pharmaceutical nanocarriers for cancer therapy and imaging. AAPS J. 2007, 9, E128-E147. [CrossRef] [PubMed]

9. Su, S.; Kang, P.M. Systemic Review of Biodegradable Nanomaterials in Nanomedicine. Nanomaterials 2020, 10, 656. [CrossRef]

10. Michalet, X.; Pinaud, F.F.; Bentolila, L.A.; Tsay, J.M.; Doose, S.; Li, J.J.; Sundaresan, G.; Wu, A.M.; Gambhir, S.S.; Weiss, S. Quantum Dots for Live Cells, in Vivo Imaging, and Diagnostics. Science 2005, 307, 538-544. [CrossRef]

11. Wang, Y.; Hu, A. Carbon quantum dots: Synthesis, properties and applications. J. Mater. Chem. C 2014, 2, 6921. [CrossRef]

12. Bitounis, D.; Ali-Boucetta, H.; Hong, B.H.; Min, D.-H.; Kostarelos, K. Prospects and Challenges of Graphene in Biomedical Applications. Adv. Mater. 2013, 25, 2258-2268. [CrossRef] [PubMed]

13. Loh, K.P.; Bao, Q.; Eda, G.; Chhowalla, M. Graphene oxide as a chemically tunable platform for optical applications. Nat. Chem. 2010, 2, 1015-1024. [CrossRef] [PubMed]

14. Eda, G.; Lin, Y.-Y.; Mattevi, C.; Yamaguchi, H.; Chen, H.-A.; Chen, I.-S.; Chen, C.-W.; Chhowalla, M. Blue Photoluminescence from Chemically Derived Graphene Oxide. Adv. Mater. 2010, 22, 505-509. [CrossRef] [PubMed]

15. García-Betancourt, M.L.; Jiménez, S.I.R.; González-Hodges, A.; Salazar, Z.E.N.; Escalante-García, I.L.; Aparicio, J.R. Low Dimensional Nanostructures: Measurement and Remediation Technologies Applied to Trace Heavy Metals in Water. In Trace Metals in the Environment-New Approaches and Recent Advances; IntechOpen: London, UK, 2021; ISBN 978-1-83880-332-2.

16. Wallace, P.R. The Band Theory of Graphite. Phys. Rev. 1947, 71, 622-634. [CrossRef]

17. Yang, K.; Feng, L.; Liu, Z. The advancing uses of nano-graphene in drug delivery. Expert Opin. Drug Deliv. 2015, 12, 601-612. [CrossRef]

18. Goenka, S.; Sant, V.; Sant, S. Graphene-based nanomaterials for drug delivery and tissue engineering. J. Control. Release 2014, 173, 75-88. [CrossRef]

19. Trusek, A.; Kijak, E.; Granicka, L. Graphene oxide as a potential drug carrier-Chemical carrier activation, drug attachment and its enzymatic controlled release. Mater. Sci. Eng. C 2020, 116, 111240. [CrossRef]

20. Bianco, A. Graphene: Safe or Toxic? The Two Faces of the Medal. Angew. Chem. Int. Ed. 2013, 52, 4986-4997. [CrossRef]

21. Titov, A.V.; Král, P.; Pearson, R. Sandwiched Graphene-Membrane Superstructures. ACS Nano 2010, 4, 229-234. [CrossRef]

22. Garriga, R.; Herrero-Continente, T.; Palos, M.; Cebolla, V.L.; Osada, J.; Muñoz, E.; Rodríguez-Yoldi, M.J. Toxicity of Carbon Nanomaterials and Their Potential Application as Drug Delivery Systems: In Vitro Studies in Caco-2 and MCF-7 Cell Lines. Nanomaterials 2020, 10, 1617. [CrossRef]

23. Zhang, L.; Xia, J.; Zhao, Q.; Liu, L.; Zhang, Z. Functional Graphene Oxide as a Nanocarrier for Controlled Loading and Targeted Delivery of Mixed Anticancer Drugs. Small 2010, 6, 537-544. [CrossRef] [PubMed]

24. Huang, P.; Xu, C.; Lin, J.; Wang, C.; Wang, X.; Zhang, C.; Zhou, X.; Guo, S.; Cui, D. Folic Acid-conjugated Graphene Oxide loaded with Photosensitizers for Targeting Photodynamic Therapy. Theranostics 2011, 1, 240-250. [CrossRef]

25. Sun, X.; Liu, Z.; Welsher, K.; Robinson, J.T.; Goodwin, A.; Zaric, S.; Dai, H. Nano-graphene oxide for cellular imaging and drug delivery. Nano Res. 2008, 1, 203-212. [CrossRef] [PubMed]

26. Wang, Y.; Zhang, S.; Xu, T.; Zhang, T.; Mo, Y.; Liu, J.; Yan, L.; Xing, F. Ultra-sensitive and ultra-fast detection of whole unlabeled living cancer cell responses to paclitaxel with a graphene-based biosensor. Sens. Actuators B Chem. 2018, 263, 417-425. [CrossRef]

27. Biris, A.R.; Mahmood, M.; Lazar, M.D.; Dervishi, E.; Watanabe, F.; Mustafa, T.; Baciut, G.; Baciut, M.; Bran, S.; Ali, S.; et al. Novel Multicomponent and Biocompatible Nanocomposite Materials Based on Few-Layer Graphenes Synthesized on a Gold/Hydroxyapatite Catalytic System with Applications in Bone Regeneration. J. Phys. Chem. C 2011, 115, 18967-18976. [CrossRef]

28. Liu, Z.; Cai, W.; He, L.; Nakayama, N.; Chen, K.; Sun, X.; Chen, X.; Dai, H. In vivo biodistribution and highly efficient tumour targeting of carbon nanotubes in mice. Nat. Nanotechnol. 2007, 2, 47-52. [CrossRef]

29. Feng, L.; Wu, L.; Wang, J.; Ren, J.; Miyoshi, D.; Sugimoto, N.; Qu, X. Detection of a Prognostic Indicator in Early-Stage Cancer Using Functionalized Graphene-Based Peptide Sensors. Adv. Mater. 2012, 24, 125-131. [CrossRef] [PubMed]

30. Arkowski, J.; Obremska, M.; Kędzierski, K.; Sławuta, A.; Wawrzyńska, M. Applications for graphene and its derivatives in medical devices: Current knowledge and future applications. Adv. Clin. Exp. Med. 2020, 29, 1497-1504. [CrossRef] 
31. Zhang, F.; Zheng, B.; Zhang, J.; Huang, X.; Liu, H.; Guo, S.; Zhang, J. Horseradish Peroxidase Immobilized on Graphene Oxide: Physical Properties and Applications in Phenolic Compound Removal. J. Phys. Chem. C 2010, 114, 8469-8473. [CrossRef]

32. Hom, C.; Lu, J.; Liong, M.; Luo, H.; Li, Z.; Zink, J.I.; Tamanoi, F. Mesoporous Silica Nanoparticles Facilitate Delivery of siRNA to Shutdown Signaling Pathways in Mammalian Cells. Small 2010, 6, 1185-1190. [CrossRef]

33. Sanchez, V.C.; Pietruska, J.R.; Miselis, N.R.; Hurt, R.H.; Kane, A.B. Biopersistence and potential adverse health impacts of fibrous nanomaterials: What have we learned from asbestos? Wiley Interdiscip. Rev. Nanomed. Nanobiotechnol. 2009, 1, 511-529. [CrossRef] [PubMed]

34. Kotchey, G.P.; Allen, B.L.; Vedala, H.; Yanamala, N.; Kapralov, A.A.; Tyurina, Y.Y.; Klein-Seetharaman, J.; Kagan, V.E.; Star, A. The Enzymatic Oxidation of Graphene Oxide. ACS Nano 2011, 5, 2098-2108. [CrossRef]

35. Banerjee, A.N. Graphene and its derivatives as biomedical materials: Future prospects and challenges. Interface Focus 2018, 8 , 20170056. [CrossRef]

36. Zhang, S.; Yang, K.; Feng, L.; Liu, Z. In vitro and in vivo behaviors of dextran functionalized graphene. Carbon 2011, 49, 4040-4049. [CrossRef]

37. Yue, H.; Wei, W.; Yue, Z.; Wang, B.; Luo, N.; Gao, Y.; Ma, D.; Ma, G.; Su, Z. The role of the lateral dimension of graphene oxide in the regulation of cellular responses. Biomaterials 2012, 33, 4013-4021. [CrossRef] [PubMed]

38. Kroto, H.W.; Allaf, A.W.; Balm, S.P. C60: Buckminsterfullerene. Chem. Rev. 1991, 91, 1213-1235. [CrossRef]

39. Sergio, M.; Behzadi, H.; Otto, A.; van der Spoel, D. Fullerenes toxicity and electronic properties. Environ. Chem. Lett. 2013, 11, 105-118. [CrossRef]

40. Ken, K.; Nozomi, S.; Sakurai, H. Colloidal Gold Nanoparticles Stabilized By Hydroxylated Fullerenes. ECS Meet. Abstr. 2017, 851. [CrossRef]

41. Xu, Z.; Liang, Z.; Ding, F. Isomerization of sp 2 -hybridized carbon nanomaterials: Structural transformation and topological defects of fullerene, carbon nanotube, and graphene. WIREs Comput. Mol. Sci. 2017, 7, e1283. [CrossRef]

42. Yadav, J. Fullerene: Properties, Synthesis and Application. Res. Rev. J. Phys. 2017, 6, 1-6.

43. Prylutska, S.V.; Grebinyk, A.G.; Lynchak, O.V.; Byelinska, I.V.; Cherepanov, V.V.; Tauscher, E.; Matyshevska, O.P.; Prylutskyy, Y.I.; Rybalchenko, V.K.; Ritter, U.; et al. In vitro and in vivo toxicity of pristine C60 fullerene aqueous colloid solution. Fuller. Nanotub. Carbon Nanostructures 2019, 27, 715-728. [CrossRef]

44. Li, T.; Murphy, S.; Kiselev, B.; Bakshi, K.S.; Zhang, J.; Eltahir, A.; Zhang, Y.; Chen, Y.; Zhu, J.; Davis, R.M.; et al. A New Interleukin-13 Amino-Coated Gadolinium Metallofullerene Nanoparticle for Targeted MRI Detection of Glioblastoma Tumor Cells. J. Am. Chem. Soc. 2015, 137, 7881-7888. [CrossRef]

45. Liu, J.; Ohta, S.; Sonoda, A.; Yamada, M.; Yamamoto, M.; Nitta, N.; Murata, K.; Tabata, Y. Preparation of PEG-conjugated fullerene containing $\mathrm{Gd}^{3+}$ ions for photodynamic therapy. J. Control. Release 2007, 117, 104-110. [CrossRef]

46. Tabata, Y.; Ikada, Y. Biological functions of fullerene. Pure Appl. Chem. 1999, 71, 2047-2053. [CrossRef]

47. Chen, Z.; Ma, L.; Liu, Y.; Chen, C. Applications of Functionalized Fullerenes in Tumor Theranostics. Theranostics 2012, 2, 238-250. [CrossRef]

48. Sharma, S.K.; Chiang, L.Y.; Hamblin, M.R. Photodynamic therapy with fullerenes in vivo: Reality or a dream? Nanomedicine 2011, 6, 1813-1825. [CrossRef]

49. Garrigue, P.; Delville, M.-H.; Labrugère, C.; Cloutet, E.; Kulesza, P.J.; Morand, J.P.; Kuhn, A. Top-Down Approach for the Preparation of Colloidal Carbon Nanoparticles. Chem. Mater. 2004, 16, 2984-2986. [CrossRef]

50. Alam, A.; Wan, C.; McNally, T. Surface amination of carbon nanoparticles for modification of epoxy resins: Plasma-treatment vs wet-chemistry approach. Eur. Polym. J. 2017, 87, 422-448. [CrossRef]

51. Fiorito, S.; Serafino, A.; Andreola, F.; Togna, A.; Togna, G. Toxicity and Biocompatibility of Carbon Nanoparticles. J. Nanosci. Nanotechnol. 2006, 6, 591-599. [CrossRef]

52. Liu, Z.; Tabakman, S.; Welsher, K.; Dai, H. Carbon nanotubes in biology and medicine: In vitro and in vivo detection, imaging and drug delivery. Nano Res. 2009, 2, 85-120. [CrossRef]

53. Kostarelos, K.; Lacerda, L.; Pastorin, G.; Wu, W.; Wieckowski, S.; Luangsivilay, J.; Godefroy, S.; Pantarotto, D.; Briand, J.-P.; Muller, S.; et al. Cellular uptake of functionalized carbon nanotubes is independent of functional group and cell type. Nat. Nanotechnol. 2007, 2, 108-113. [CrossRef] [PubMed]

54. Lacerda, L.; Raffa, S.; Prato, M.; Bianco, A.; Kostarelos, K. Cell-penetrating CNTs for delivery of therapeutics. Nano Today 2007, 2 , 38-43. [CrossRef]

55. Marchesan, S.; Kostarelos, K.; Bianco, A.; Prato, M. The winding road for carbon nanotubes in nanomedicine. Mater. Today 2015, 18, 12-19. [CrossRef]

56. Sheikhpour, M.; Naghinejad, M.; Kasaeian, A.; Lohrasbi, A.; Shahraeini, S.S.; Zomorodbakhsh, S. The Applications of Carbon Nanotubes in the Diagnosis and Treatment of Lung Cancer: A Critical Review. Int. J. Nanomed. 2020, 15, 7063-7078. [CrossRef]

57. Golubewa, L.; Timoshchenko, I.; Romanov, O.; Karpicz, R.; Kulahava, T.; Rutkauskas, D.; Shuba, M.; Dementjev, A.; Svirko, Y.; Kuzhir, P. Single-walled carbon nanotubes as a photo-thermo-acoustic cancer theranostic agent: Theory and proof of the concept experiment. Sci. Rep. 2020, 10, 22174. [CrossRef]

58. Hartman, K.B.; Laus, S.; Bolskar, R.D.; Muthupillai, R.; Helm, L.; Toth, E.; Merbach, A.E.; Wilson, L.J. Gadonanotubes as Ultrasensitive pH-Smart Probes for Magnetic Resonance Imaging. Nano Lett. 2008, 8, 415-419. [CrossRef] 
59. Choi, J.H.; Nguyen, F.T.; Barone, P.W.; Heller, D.A.; Moll, A.E.; Patel, D.; Boppart, S.A.; Strano, M.S. Multimodal Biomedical Imaging with Asymmetric Single-Walled Carbon Nanotube/Iron Oxide Nanoparticle Complexes. Nano Lett. 2007, 7, 861-867. [CrossRef]

60. Wang, H.; Wang, J.; Deng, X.; Sun, H.; Shi, Z.; Gu, Z.; Liu, Y.; Zhaoc, Y. Biodistribution of Carbon Single-Wall Carbon Nanotubes in Mice. J. Nanosci. Nanotechnol. 2004, 4, 1019-1024. [CrossRef]

61. Chłopek, J.; Czajkowska, B.; Szaraniec, B.; Frackowiak, E.; Szostak, K.; Béguin, F. In vitro studies of carbon nanotubes biocompatibility. Carbon 2006, 44, 1106-1111. [CrossRef]

62. Murphy, F.A.; Poland, C.A.; Duffin, R.; Donaldson, K. Length-dependent pleural inflammation and parietal pleural responses after deposition of carbon nanotubes in the pulmonary airspaces of mice. Nanotoxicology 2012, 7, 1157-1167. [CrossRef]

63. Cataldo, F.; Da Ros, T. (Eds.) Carbon Materials: Chemistry and Physics. In Medicinal Chemistry and Pharmacological Potential of Fullerenes and Carbon Nanotubes; Springer: Dordrecht, The Netherlands, 2008; Volume 1, ISBN 978-1-4020-6844-7.

64. Heller, D.A.; Baik, S.; Eurell, T.E.; Strano, M.S. Single-Walled Carbon Nanotube Spectroscopy in Live Cells: Towards Long-Term Labels and Optical Sensors. Adv. Mater. 2005, 17, 2793-2799. [CrossRef]

65. Lacerda, L.; Russier, J.; Pastorin, G.; Herrero, M.A.; Venturelli, E.; Dumortier, H.; Al-Jamal, K.T.; Prato, M.; Kostarelos, K.; Bianco, A. Translocation mechanisms of chemically functionalised carbon nanotubes across plasma membranes. Biomaterials 2012, 33, 3334-3343. [CrossRef] [PubMed]

66. Xu, X.; Ray, R.; Gu, Y.; Ploehn, H.J.; Gearheart, L.; Raker, K.; Scrivens, W.A. Electrophoretic Analysis and Purification of Fluorescent Single-Walled Carbon Nanotube Fragments. J. Am. Chem. Soc. 2004, 126, 12736-12737. [CrossRef] [PubMed]

67. Sun, Y.-P.; Zhou, B.; Lin, Y.; Wang, W.; Fernando, K.A.S.; Pathak, P.; Meziani, M.J.; Harruff, B.A.; Wang, X.; Wang, H.; et al. Quantum-Sized Carbon Dots for Bright and Colorful Photoluminescence. J. Am. Chem. Soc. 2006, 128, 7756-7757. [CrossRef]

68. Nair, A.; Haponiuk, J.T.; Thomas, S.; Gopi, S. Natural carbon-based quantum dots and their applications in drug delivery: A review. Biomed. Pharmacother. 2020, 132, 110834. [CrossRef] [PubMed]

69. Singh, R.; Singh, R.K. Fungi-derived carbon quantum dots: A fluorescent detector for toxic heavy metal ion detection. In New and Future Developments in Microbial Biotechnology and Bioengineering; Elsevier: Amsterdam, The Netherlands, 2020 ; pp. 159-165.

70. Liu, J.; Li, R.; Yang, B. Carbon Dots: A New Type of Carbon-Based Nanomaterial with Wide Applications. ACS Cent. Sci. 2020, 6, 2179-2195. [CrossRef]

71. Wu, F.; Su, H.; Wang, K.; Wong, W.-K.; Zhu, X. Facile synthesis of N-rich carbon quantum dots from porphyrins as efficient probes for bioimaging and biosensing in living cells. Int. J. Nanomed. 2017, 12, 7375-7391. [CrossRef]

72. Qu, S.; Zhou, D.; Li, D.; Ji, W.; Jing, P.; Han, D.; Liu, L.; Zeng, H.; Shen, D. Toward Efficient Orange Emissive Carbon Nanodots through Conjugated sp2-Domain Controlling and Surface Charges Engineering. Adv. Mater. 2016, 28, 3516-3521. [CrossRef]

73. Wu, F.; Yue, L.; Su, H.; Wang, K.; Yang, L.; Zhu, X. Carbon Dots @ Platinum Porphyrin Composite as Theranostic Nanoagent for Efficient Photodynamic Cancer Therapy. Nanoscale Res. Lett. 2018, 13, 357. [CrossRef]

74. Zheng, M.; Liu, S.; Li, J.; Qu, D.; Zhao, H.; Guan, X.; Hu, X.; Xie, Z.; Jing, X.; Sun, Z. Integrating Oxaliplatin with Highly Luminescent Carbon Dots: An Unprecedented Theranostic Agent for Personalized Medicine. Adv. Mater. 2014, 26, 3554-3560. [CrossRef]

75. Wu, F.; Su, H.; Zhu, X.; Wang, K.; Zhang, Z.; Wong, W.-K. Near-infrared emissive lanthanide hybridized carbon quantum dots for bioimaging applications. J. Mater. Chem. B 2016, 4, 6366-6372. [CrossRef]

76. Wu, F.; Yue, L.; Yang, L.; Wang, K.; Liu, G.; Luo, X.; Zhu, X. Ln(III) chelates-functionalized carbon quantum dots: Synthesis, optical studies and multimodal bioimaging applications. Colloids Surf. B Biointerfaces 2019, 175, 272-280. [CrossRef]

77. Ko, N.R.; Nafiujjaman, M.; Lee, J.S.; Lim, H.-N.; Lee, Y.-K.; Kwon, I.K. Graphene quantum dot-based theranostic agents for active targeting of breast cancer. RSC Adv. 2017, 7, 11420-11427. [CrossRef]

78. Lim, S.Y.; Shen, W.; Gao, Z. Carbon quantum dots and their applications. Chem. Soc. Rev. 2015, 44, 362-381. [CrossRef]

79. Rosenthal, S.J.; Chang, J.C.; Kovtun, O.; McBride, J.R.; Tomlinson, I.D. Biocompatible Quantum Dots for Biological Applications. Chem. Biol. 2011, 18, 10-24. [CrossRef] [PubMed]

80. Chung, S.; Revia, R.A.; Zhang, M. Graphene Quantum Dots and Their Applications in Bioimaging, Biosensing, and Therapy. Adv. Mater. 2021, 33, 1904362. [CrossRef] [PubMed]

81. Fusco, L.; Gazzi, A.; Peng, G.; Shin, Y.; Vranic, S.; Bedognetti, D.; Vitale, F.; Yilmazer, A.; Feng, X.; Fadeel, B.; et al. Graphene and other 2D materials: A multidisciplinary analysis to uncover the hidden potential as cancer theranostics. Theranostics 2020, 10, 5435-5488. [CrossRef]

82. Zhao, C.; Song, X.; Liu, Y.; Fu, Y.; Ye, L.; Wang, N.; Wang, F.; Li, L.; Mohammadniaei, M.; Zhang, M.; et al. Synthesis of graphene quantum dots and their applications in drug delivery. J. Nanobiotechnol. 2020, 18, 142. [CrossRef]

83. Liu, J.; Zhang, R.; Xu, Z.P. Nanoparticle-Based Nanomedicines to Promote Cancer Immunotherapy: Recent Advances and Future Directions. Small 2019, 15, 1900262. [CrossRef] [PubMed] 